\title{
The relationship between students' perceptions of the University of Pretoria's on-campus green spaces and attention restoration
}

\author{
Ruth M Liprini*, Nicoleen Coetzee
}

University of Pretoria, South Africa

Previous research has suggested that natural green areas provide several psychological benefits to individuals. One such benefit is the restoration of attention capacities, an advantage that is of particular importance to university students. The present study, therefore, aimed to determine where students spend their free time on campus at the University of Pretoria, South Africa, how they perceive their on-campus green spaces and the extent to which they found these spaces restorative. Participants responded to a threepart questionnaire, investigating demographic characteristics, green space usage, and the Perceived Restorativeness Scale (PRS). Statistical analyses were conducted to determine which of the green spaces contributed most significantly to overall PRS scores. All green areas made significant contributions, but the campus's botanical garden was the greatest contributor to PRS. The findings of this study serve to encourage tertiary institutions to protect their green spaces, as the psychological well-being and attention restoration of students are affected by it.

Key Words: attention restoration, green spaces, perceived restorativeness, psychological wellbeing, students, university campus.

Article Info: Received: July 4, 2017; Revised: November 5, 2017; Accepted: November 15, 2017; Online: November 25, 2017.

\section{Introduction}

Speake, Edmondson, \& Nawaz (2013) conducted research to determine where students at Liverpool Hope University in England chose to spend their free

\section{* Corresponding author}

Address: Department of Psychology, University of Pretoria, Private bag X20, Hatfield 0028, South Africa.

Phone: +27826340708 | Email: ruth@periziaconsulting.co.za

(C)2017 Human Geographies; The authors

(c) (1) This work is licensed under a

Creative Commons Attribution 4.0 International License. DOI:10.5719/hgeo.2017.112.2 
time. The researchers discovered that more than half of their participants chose to spend their free time in green spaces near classrooms. In a similar study done by Liprini (2014) at the University of Pretoria in South Africa, 80.4\% of the participants indicated that they preferred to spend their free time outdoors in green spaces.

Green space is defined by the Merriam-Webster (2014) online dictionary as a 'community space consisting of land (as parks) rather than buildings'. Landscape designers perceive green spaces as part of soft landscapes that include trees, shrubs, ground cover, and gardens (Shah, Kale \& Patki, 2002). Hard landscapes, on the other hand, refer to the built environment, such as paved surfaces, buildings, walkways, and so forth (Shah et al., 2002).

When students have been asked, in various studies, why they prefer to spend their free time in green spaces, most indicated that the green spaces facilitate social interaction more than the hard landscapes on their campuses (AbuGhazzeh, 1999; Maas, Van Dillen, Verheij \& Groenewegen, 2009; Speake et al., 2013). It is interesting to note that when students were queried about their use of green spaces, many stated that they were attracted to the green and 'park-like' features. Students also noted that they particularly liked the presence of trees and grass (Abu-Ghazzeh, 1999).

McFarland, Waliczek \& Zajicek (2008) postulated that students' affinity for green spaces involved significantly more than simply offering them places for social interaction and environments they were attracted to. The researchers conducted a study to determine if there was a relationship between green space usage and Perceived Quality of Life (PQoL). The measurement used in the study consisted of an affective domain (measuring dimensions of total positive affect, interaction with other students, and interaction with professors), and a cognitive domain (measuring the extent to which students felt they were experiencing sufficiently 'demanding cognitive challenges') (McFarland et al., 2008). Significant positive correlations were found between the amount of time spent in green spaces and PQoL, and the amount of time spent in green spaces and the affective domain. In addition, a significant positive correlation was discovered between the cognitive domain and the amount of time spent in green spaces. The researchers concluded that the students who spend more time in green spaces were better able to deal with academic challenges and were better equipped to apply knowledge learned, than those who spent less time in these areas (McFarland et al., 2008).

Kaplan and Kaplan (1989) theorised that attention restoration is the process whereby exposure to green spaces assists in the restoration of an individual's attention. According to the Attention Restoration Theory (ART), natural environments should exhibit four types of characteristics to assist in this process. The first characteristic is being away. A landscape should induce a sense of escape from one's daily routine and distractions. Secondly, a landscape should have extent, whereby it invokes the imagination by promising more than can be seen at a cursory glance. An example of this may be found in a forest trail: one is aware there is more to be seen as one progresses down the trail, but it cannot initially be seen. It is important that a landscape invokes fascination: an interesting stimulus that requires only involuntary attention. A stimulus that requires involuntary attention but still allows the individual room for mental reflection is 
ideal for attention restoration. Finally, a landscape needs to be compatible with the desires of the individual. The green space needs to support the intended function of the individual. Each of the aforementioned characteristics in isolation can assist in restoration, but maximum benefit is obtained when all four are present. Berman, Jonides \& Kaplan (2008) supported the notion of attention restoration and stated that natural environments play a large role in the restoration of directed attention by the induction of involuntary attention. Herzog, Black, Fountaine \& Knotts (1997) had previously tested this notion by studying the responses of 187 undergraduate students. Their study aimed to compare the perceived restorativeness of non-university landscapes - both natural (soft landscapes) and urban (hard landscapes). The results showed that the natural environment uniformly had the highest perceived restorativeness rating (Herzog et al., 1997).

Felsten (2009), however, contended that both real and non-real natural settings (such as murals of natural settings) would have a restorative effect on students who were cognitively depleted after classes. The results did not fully support his notions and indicated that dramatic nature scenes had a greater restorative effect than mundane real and non-real nature settings (Felsten, 2009). He insisted, however, that non-real nature settings did have a restorative effect to some extent.

Kjellgren \& Buhrkall (2010) on the other hand, contested Felsten's (2009) findings and suggested that the essence of the natural environment - whether it is, in fact, natural or not - was key in the effectiveness of attention restoration. They conducted a mixed-method study during which participants were exposed to 30 minutes of either a natural environment or an indoor simulation of the natural environment. Their results revealed that the real natural environments induced the highest levels of restoration and increased energy (Kjellgren \& Buhrkall, 2010).

From reviewing the above studies and their results, it may be surmised that the use of green spaces may indirectly improve students' attention restoration. With the fall of apartheid and the initiation of inclusive access to tertiary education, the University of Pretoria, well known for its large amount of green spaces, is under pressure to expand its learning space. This has resulted in the construction of additional buildings on some of its campuses. As a result, the amount of green space had decreased. Since South Africa's population differs significantly from others around the world, one cannot simply accept that international research findings on green space use and its relationship with attention restoration can be applied to the South African setting. It was therefore decided to conduct a study on the impact of green spaces on ART in the South African context, incorporating the University of Pretoria's campus.

In order to determine this, the first objective of the present study was to investigate if students at the University of Pretoria spend their free time in green spaces, and if they do, to what extent they perceive such spaces as restorative. Another objective of the study was to ascertain if it emerged that the green spaces were related to attention restoration, which green space could be deemed the most restorative.

Previous studies highlighted only the fact that students were attracted to green spaces and indicated that these spaces facilitated social interaction and 
improved PQoL. Other studies further looked at how green spaces facilitate attention restoration, but none specifically examined the restorativeness of oncampus green spaces. The present study will, therefore, show that on-campus green spaces are necessary for the attention restoration of students, helping them deal more effectively with the cognitive load that attending lectures and writing exams places on them. It will consequently be proven that on-campus green spaces are necessary and should be preserved.

\section{Method}

\section{Participants}

One of the biggest campuses of the University of Pretoria with a large amount of green space is the Hatfield Campus situated in Pretoria, Gauteng. Convenience sampling was used to obtain 286 participants who were full-time students at the campus. Most of the participants were female $(n=178)$. Their ages ranged from 19 to 25 years and older.

\section{Instruments}

The measurement instrument used in this study was a questionnaire that comprised three parts. The first part consisted of questions on demographic information, the second part addressed green space usage, and the third part comprised the Perceived Restorativeness Scale (PRS).

The demographic section: This section included questions related to age, gender, race, and degree for which the student was enrolled.

Green space usage: This section of the questionnaire included questions related to green space usage. It consisted of closed-ended, open-ended, and Likert-scale type questions. Closed-ended questions were used to determine how much free time students spent on campus. The five-point Likert scale questions were used to establish the extent to which the participants enjoy spending time in green spaces, and the open-ended questions allowed participants to provide suggestions for the improvement of the green spaces on campus.

The Perceived Restorativeness Scale (PRS): The PRS is a 26-item scale that measures the four core constructs of Attention Restoration Theory. It aims to determine the perceived extent of restorativeness various green spaces induce in individuals. It allows for a maximum score of 120, where the higher scores indicate a higher perceived level of restorativeness. Cronbach's alpha values for the PRS ranged over many studies from $a=.71$ to $a=.93$ (Galindo \& Hidalgo, 2005; Korpela \& Hartig, 1996; Korpela, Hartig, Kaiser \& Fuhrer, 2001; Purcell, Peron \& Berto, 2001; Tenngart Ivarsson \& Hagerhall, 2008). A review of the scale indicated that two items were not applicable to the South African context and were consequently omitted. Despite removing these two items, the PRS still obtained a Cronbach alpha value of $a=.92$ for the present study.

\section{Procedure}

Data was collected in lecture venues during the final portion of lecture time. Permission was obtained from Heads of Departments and relevant lecturers to 
Table 1. Frequency Distribution of Time Spent on Campus

\begin{tabular}{lcccc}
\hline $\begin{array}{l}\text { Amount of Time } \\
\text { Spent on Campus }\end{array}$ & Frequency & Percentage & $\begin{array}{c}\text { Valid } \\
\text { Percentage }\end{array}$ & $\begin{array}{l}\text { Cumulative } \\
\text { Percentage }\end{array}$ \\
\hline None & 19 & 6.6 & 6.6 & 6.6 \\
\hline $15-30$ minutes & 39 & 13.6 & 13.6 & 20.3 \\
\hline 30 minutes - 1 hour & 59 & 20.6 & 20.6 & 40.9 \\
\hline $1-2$ hours & 53 & 18.5 & 18.5 & 59.4 \\
\hline $2+$ hours & 116 & 40.6 & 40.6 & 100.0 \\
\hline Total & $\mathbf{2 8 6}$ & $\mathbf{1 0 0 . 0}$ & $\mathbf{1 0 0 . 0}$ & \\
\hline
\end{tabular}

use this timeslot. The nature of the study was explained to the students. Those who were willing to participate received information sheets and then signed informed consent forms. They then received the questionnaire and returned it once completed. This procedure took approximately 15 minutes.

\section{Ethical considerations}

The research was approved by the Ethics Committee of the Faculty of Humanities at the University of Pretoria. Informed consent was obtained from all participants before they were included in the study. Participation was voluntary, and privacy was respected at all times. Participants were free to withdraw at any time without consequence. Confidentiality was ensured by not obtaining any personal information that could identify any participant, and instead providing them with a participant number.

\section{Data analysis}

Data were analysed using the Statistical Package for the Social Sciences (SPSS) Version 21@. Descriptive statistics were obtained to better understand the sample population as well as the frequency of responses to the Likert-scale questions. Both parametric and non-parametric statistics were utilised during the process of data analysis, including Spearman's correlation, a one-way ANOVA, and multiple regression analysis.

\section{Results}

All students were asked to indicate how much time they spend on campus, outside of lectures. Frequency distribution analyses were conducted to this end. Table 1 indicates that most of the participants spend two or more hours on campus. Students were then asked to indicate whether they prefer to spend their free time indoors or outdoors, of which $80.4 \%$ indicated that they prefer to spend time outdoors $(n=230)$. They were then required to indicate whether they voluntarily spend their free time on campus in green spaces. This served as a qualifying question in that those who responded 'no' were not required to continue with the questionnaire. Of those who responded 'yes', students were required to indicate where they spent their free time. This was a multiple choice question with an 'other' option. Frequency analyses were conducted to determine which green spaces were most utilised. Table 2 is the list of responses.

The following are images and associated descriptions of each of the chosen green spaces mentioned in table 2. The Aula grass (Option A) is a large, rectan- 
Table 2. Frequency Distribution of Selected Green Spaces

\begin{tabular}{lcccc}
\hline \multicolumn{1}{c}{ Chosen Green Space } & Frequency Percentage & $\begin{array}{c}\text { Valid } \\
\text { Percentage }\end{array}$ & $\begin{array}{c}\text { Cumulative } \\
\text { Percentage }\end{array}$ \\
\hline Aula Grass (Option A) & 29 & 10.1 & 11.8 & 11.8 \\
\hline Stone steps at Music (Option B) & 46 & 16.1 & 18.8 & 30.6 \\
\hline Theology grass (Option C) & 20 & 7.0 & 8.2 & 38.8 \\
\hline CSC grass (Option D) & 47 & 16.4 & 19.2 & 58.0 \\
\hline IT grass (Option E) & 5 & 1.7 & 2.0 & 60.0 \\
\hline Ou Merensky grass (Option F) & 15 & 5.2 & 6.1 & 66.1 \\
\hline $\begin{array}{l}\text { Manie van der Schijff botanical } \\
\text { garden (Option G) }\end{array}$ & 20 & 7.0 & 8.2 & 74.3 \\
\hline Other (Option H) & 63 & 22.0 & 25.7 & $\mathbf{1 0 0 . 0}$ \\
\hline Total & $\mathbf{2 4 5}$ & 85.7 & $\mathbf{1 0 0 . 0}$ & \\
\hline Missing & 41 & 14.3 & & \\
\hline Total & $\mathbf{2 8 6}$ & $\mathbf{1 0 0 . 0}$ & & \\
\hline
\end{tabular}

gular, grassy area in front of the university's prominent Aula building. Shrubs and trees border the area (Photo 1). The stone steps at the Music department (Option B) are outside of the music auditorium and overlook a well-maintained garden outside of the music department. The central feature of this garden is a water fountain surrounded by scarlet sage (Photo 2). The Theology grass (Option C), the Theology department is in a quiet, secluded area. It has a grassy pathway between shrubs and trees and it is used by students for relaxation

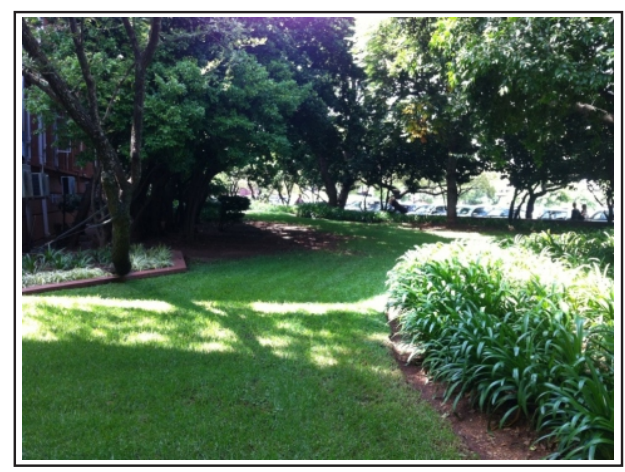

Photo 1. The Aula grass (Option A)

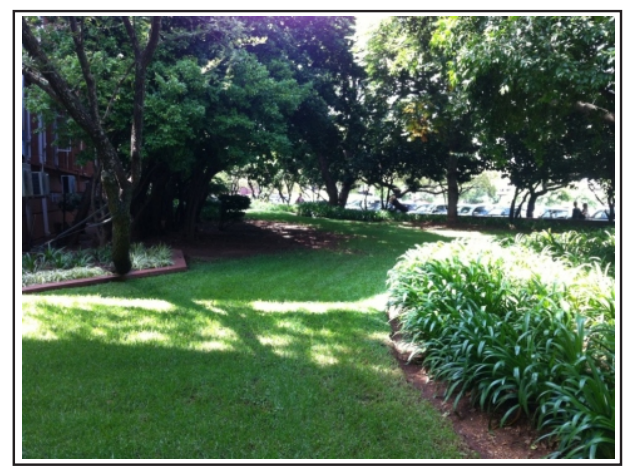

Photo 3. The Theology grass (Option C)

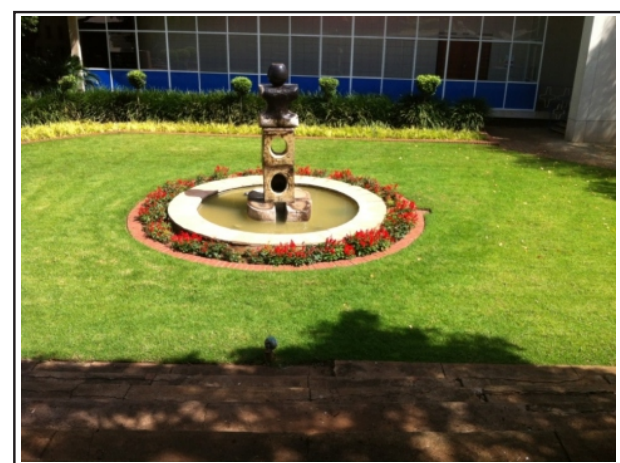

Photo 2. The stone steps at the Music department (Option B)

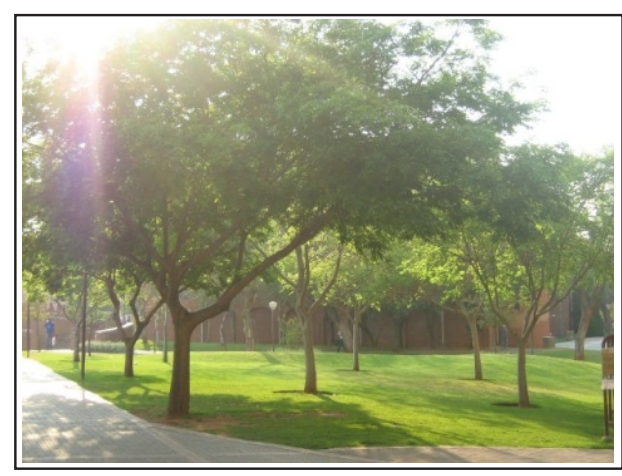

Photo 4. The Client Service Centre grass (Option D) 


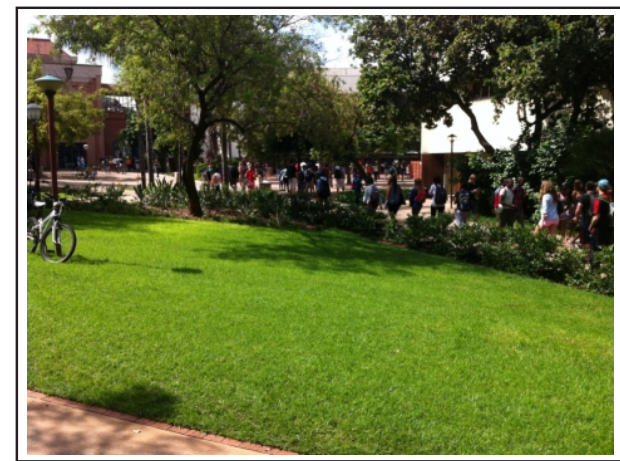

Photo 5. The IT grass (Option E)

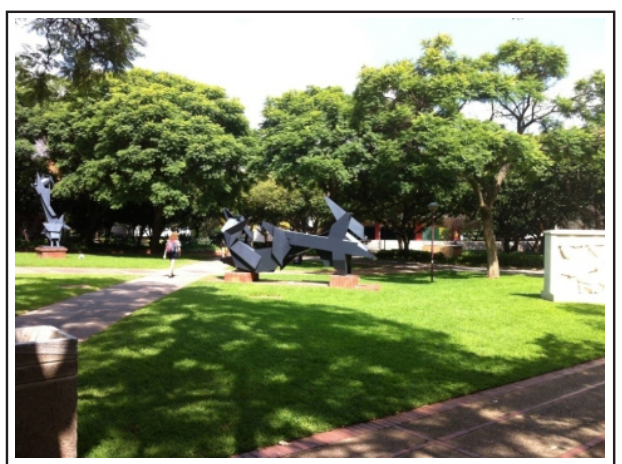

Photo 6. The Old Merensky grass (Option F)

purposes (Photo 3). The Client Service Centre (CSC) grass (Option D) is the central focus of the campus. The green space is behind the CSC, and behind that is the food court. It is a busy open space on an incline and trees placed approximately $5 \mathrm{~m}$ apart provide shade (Photo 4). The IT grass (Option E), this green space, situated between the Economic and Management Sciences building and the IT building is a narrow grassy strip bordered by strelitzias and shrubs. These buildings are situated to the right of the CSC when looking at the campus from the front. This is a busy area, as beyond the grass is a walkway leading to the east exit that is frequently used (Photo 5). The Old Merensky grass (Option F), is situated in front of the Old Merensky, which is the University's old library that has since been declared a national monument. There are walkways bordering this area, but they are not intrusive. There are pathways connecting this area to the west side of the campus (Photo 6).

The Manie van der Schijff botanical garden (Option G) has about 3,000 plant species, planted over approximately 3.5 hectares of the Hatfield campus. Many students spend time in the grassy areas between the trees and flowers. Is a very secluded area and is situated towards the older part of campus that is not used often anymore. The garden has one side that is elevated, heightening the sense of solitude (Photo 7).

It is evident from table 2 that the most popular green space is the CSC grass $(n=47)$. The second most popular area is 'the stone steps at Music' $(n=46)$. The Aula grass is the third most popular area $(n=29)$. This grassy area is the largest continuous green space on campus with trees lining the perimeter of the grass. The lack of shade inside the perimeter could potentially be part of the reason why it is not a more popular area. Additionally, it was mentioned that this area is not often available due to the perceived constant presence of unpleasant smelling fertiliser.

Other than the green areas mentioned above, table 2 expresses that the most popular response was 'other'. This response was not included in the discussion above as it is not an identifiable green space in and of itself. Nonetheless, the popularity of this response led to the compilation of a frequency analysis to uncover other popular green areas. During the process of data capturing, it became evident that not all students fully understand the concept of green space. One common response among architecture students was 'the stone steps overlooking the parking lot outside Boukunde'. This area includes the entrance 


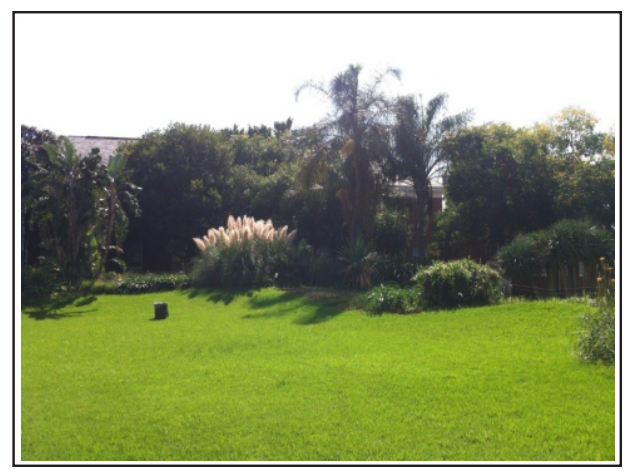

Photo 7. The Manie van der Schiiff botanical garden (Option G)

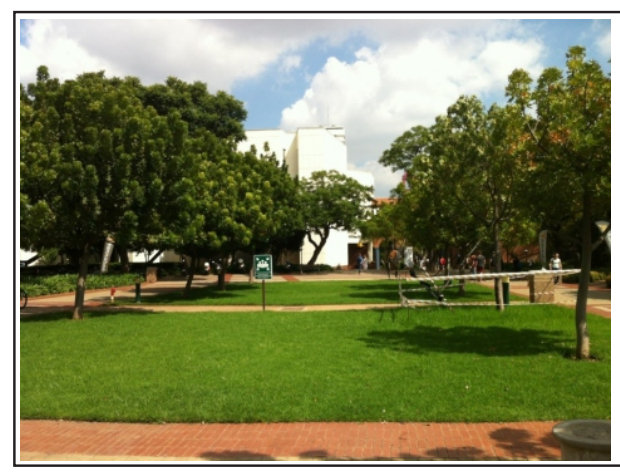

Photo 8. The grass opposite Oom Gert's se Plek (in option "Other")

Table 3. One-way ANOVA of Time Spent on Campus and PRS Scores

\begin{tabular}{lccccc}
\hline \multicolumn{7}{c}{ Perceived Restorativeness Scale } \\
\hline & Sum of Squares & Df & Mean Square & F & Sig. \\
\hline Between Groups & 1094.022 & 4 & 273.505 & 1.171 & .324 \\
\hline Within Groups & 54671.677 & 234 & 233.640 & & \\
\hline Total & $\mathbf{5 5 7 6 5 . 6 9 9}$ & $\mathbf{2 3 8}$ & & & \\
\hline
\end{tabular}

doors to the Architecture building, stone steps and a (usually full) parking lot. As such, it would not generally be classified as a green space. The most popular response under the list of 'other' responses was 'the grass opposite Oom Gert se Plek' (Photo 8).

The grass opposite Oom Gert's se Plek (in option 'Other'): Oom Gert's is a popular on-campus pub-style restaurant, and the grassy area referred to is situated between the restaurant and the Agriculture Annex building. The Agriculture Annex is situated on the campus's East border and is separated from other main campus buildings. The grass opposite Oom Gert's is a primarily grassy area intersected by paths and a few small trees.

As previously discussed, the Perceived Restorativeness Scale was used to determine the extent to which students deem on-campus green spaces as restorative. This 24 -item scale had a reliability rating of $\alpha=.92$, and the results of the Kolmogorov-Smirnov test indicated that the data were normally distributed $(p=0.687)$. Spearman's correlation was then conducted to determine whether there was a correlation between the amount of time spent on campus and total PRS scores. The resultant correlation coefficient of $r=.099$ and Sig. (2-tailed) value of 0.126 revealed no significant correlations in this regard. This was subsequently followed up with a one-way ANOVA to determine if there were any significant differences between the amount of time spent on campus and PRS scores.

Table 3 indicates that there are no significant differences between the amount of time spent on campus and PRS scores $(p>0.05)$.

Despite the non-significant results, a decision was made to establish whether significant differences occurred between green spaces and their mean PRS scores. It was initially anticipated that each of the green spaces listed in Table 2 would attract an equal number of responses. This was not, however, the case and as such, green spaces were grouped together based on their proximity to 
Table 4. Basic Descriptive Statistics of Newly Grouped Green Spaces

\begin{tabular}{lccc}
\hline \multicolumn{1}{c}{ Newly Grouped Green Spaces } & PRS Mean Score & N & SD \\
\hline Area A & 86.9091 & 44 & 13.48525 \\
\hline Area B & 86.2656 & 64 & 14.72202 \\
\hline Area C & 86.4222 & 45 & 12.89378 \\
\hline Area D & 85.4000 & 25 & 12.31530 \\
\hline Area E & 95.7895 & 19 & 14.02608 \\
\hline Other & 77.1905 & 42 & 18.94825 \\
\hline Total & $\mathbf{8 5 . 4 8 5 4}$ & $\mathbf{2 3 9}$ & $\mathbf{1 5 . 3 0 7 1 8}$ \\
\hline
\end{tabular}

Table 5. One-way ANOVA between green spaces and their mean PRS scores

\begin{tabular}{lccccc}
\hline \multicolumn{7}{c}{ Perceived Restorativeness Scale } \\
\hline & Sum of Squares & Df & Mean Square & F & Sig. \\
\hline Between Groups & 5074.966 & 5 & 1014.993 & 4.665 & .000 \\
\hline Within Groups & 50690.733 & 233 & 217.557 & & \\
\hline Total & $\mathbf{5 5 7 6 5 . 6 9 9}$ & $\mathbf{2 3 8}$ & & & \\
\hline
\end{tabular}

one another to allow for further data analysis. The new areas were grouped as follow to establish Areas A - E:

Area A = The Aula grass + The Ou Merensky grass;

Area $\mathrm{B}=$ Stone steps at the Music Department + the Theology grass;

Area $\mathrm{C}=$ The CSC grass;

Area $\mathrm{D}=$ The IT grass + the grass outside Oom Gert's se Plek;

Area E = The Manie van der Schijff botanical garden.

Basic descriptive statistics were computed for the newly established areas. The results are displayed in Table 4. A one-way ANOVA was conducted to establish whether significant differences occurred between green spaces and their mean PRS scores. Table 5 displays the results of this analysis. It is evident from the above that there were significant differences in PRS scores between green spaces on campus $(p \leq 0.05)$. A subsequent post-hoc multiple comparisons analysis was then carried out to determine where these differences lay. The results of this analysis are displayed in Table 6.

There were significant differences between the option 'other' $(\mathrm{M}=77.19$, $\mathrm{SD}=18.95)$ and Area $\mathrm{A}(\mathrm{M}=86.91, \mathrm{SD}=13.49)$, Area $\mathrm{B}(\mathrm{M}=86.27, \mathrm{SD}=14.72)$ and Area $\mathrm{E}(\mathrm{M}=95.79, \mathrm{SD}=14.03)$. The effect size, calculated using eta-squared was 0.09, which, according to Cohen (1988) is considered a medium effect size.

Multiple regression analysis was then carried out to determine which of the newly grouped green spaces contributed most significantly to overall PRS scores. Preliminary analysis was conducted on the data to ensure that the assumptions of normality, linearity, multicollinearity, and homoscedasticity had not been violated. After that, the multiple regression analysis was conducted. The established model yielded significant results $(p<0.05)$.

The following table provides a breakdown of the statistical contribution of each of the green spaces to overall PRS scores. Table 7 indicates that all the areas contributed significantly towards the PRS scores, with Area E (the Manie van der Schijff botanical garden) the greatest contributor (beta $=0.329, p<0.05$ ), followed by Area B (beta $=0.263, p<0.05$ ) and Area A (beta $=0.247, p<$ $0.05)$. 
Table 6. Post-hoc Multiple Comparisons between Groups

\begin{tabular}{|c|c|c|c|}
\hline \multicolumn{2}{|c|}{ Newly Grouped Green Spaces } & \multirow{2}{*}{$\begin{array}{r}\text { Mean Difference (I-J) } \\
.64347\end{array}$} & \multirow{2}{*}{$\begin{array}{l}\text { Sig. } \\
1.000\end{array}$} \\
\hline Area $\mathrm{A}$ & Area B & & \\
\hline & Area D & 1.50909 & 1.000 \\
\hline & Area C & .48687 & 1.000 \\
\hline & Area E & -8.88038 & .439 \\
\hline & Other & 9.71861 & $.038 *$ \\
\hline \multirow[t]{5}{*}{ Area B } & Area A & -.64347 & 1.000 \\
\hline & Area D & .86562 & 1.000 \\
\hline & Area C & -.15660 & 1.000 \\
\hline & Area E & -9.52385 & .213 \\
\hline & Other & 9.07515 & $.033^{*}$ \\
\hline \multirow[t]{5}{*}{ Area C } & Area A & -.48687 & 1.000 \\
\hline & Area B & 15660 & 1.000 \\
\hline & Area D & 1.02222 & 1.000 \\
\hline & Area E & -9.36725 & .317 \\
\hline & Other & 9.23175 & .058 \\
\hline \multirow[t]{5}{*}{ Area D } & Area A & -1.50909 & 1.000 \\
\hline & Area B & -.86562 & 1.000 \\
\hline & Area C & -1.02222 & 1.000 \\
\hline & Area $\mathrm{E}$ & -10.38947 & .323 \\
\hline & Other & 8.20952 & .428 \\
\hline \multirow[t]{5}{*}{ Area $\mathrm{E}$} & Area $\mathrm{A}$ & 8.88038 & .439 \\
\hline & Area B & 9.52385 & .213 \\
\hline & Area D & 10.38947 & .323 \\
\hline & Area C & 9.36725 & .317 \\
\hline & Other & 18.59900 & $.000 *$ \\
\hline \multirow[t]{5}{*}{ Other } & Area A & -9.71861 & $.038^{*}$ \\
\hline & Area B & -9.07515 & $.033^{*}$ \\
\hline & Area D & -8.20952 & .428 \\
\hline & Area C & -9.23175 & .058 \\
\hline & Area E & -18.59900 & $.000 *$ \\
\hline
\end{tabular}

* The mean difference is significant at the 0.05 level.

Table 7. Evaluation of Each Green Space

\begin{tabular}{|c|c|c|c|c|c|c|c|c|c|}
\hline \multirow{3}{*}{\multicolumn{2}{|c|}{ Model }} & \multicolumn{5}{|c|}{ Coefficients $^{a}$} & & & \\
\hline & & \multicolumn{2}{|c|}{$\begin{array}{c}\text { Unstandardised } \\
\text { Coefficients }\end{array}$} & \multirow{2}{*}{$\begin{array}{c}\begin{array}{c}\text { Standardised } \\
\text { Coefficients }\end{array} \\
\text { Beta }\end{array}$} & \multirow[b]{2}{*}{$\mathrm{T}$} & \multirow{3}{*}{$\frac{\text { Sig. }}{.000}$} & \multicolumn{3}{|c|}{ Correlations } \\
\hline & & B & Std Error & & & & $\begin{array}{l}\text { Zero- } \\
\text { order }\end{array}$ & Partial & Part \\
\hline 7 & (Constant) & 77.190 & 2.276 & & 33.916 & & & & \\
\hline & Area $\mathrm{A}$ & 9.719 & 3.182 & .247 & 3.054 & .003 & .044 & .196 & .191 \\
\hline & Area B & 9.075 & 2.929 & .263 & 3.098 & .002 & .031 & .199 & .194 \\
\hline & Area C & 9.232 & 3.165 & .236 & 2.917 & .004 & .030 & .188 & .182 \\
\hline & Area D & 8.210 & 3.726 & .164 & 2.203 & .029 & -.002 & .143 & .138 \\
\hline & Area E & 18.599 & 4.078 & .329 & 4.561 & .000 & .198 & .286 & .285 \\
\hline
\end{tabular}

aDependent Variable: Perceived Restorativeness Scale

\section{Discussion}

Green spaces, attention restoration, and psychological well-being

Table 1 indicates that most of the participants in the study spend two or more hours on campus when they are not attending lectures. Although the results do not indicate if they spend the time voluntarily on campus or out of necessity (while waiting for their next lecture), it is important to note that most of this time is spent in green spaces (table 2). This confirms Kaplan \& Kaplan's (1989) 
dated notion that individuals suffering from mental fatigue unconsciously tend to seek out green spaces to restore attention. Mental fatigue typically occurs when an individual works and/or concentrates for extended periods of time (Kaplan \& Kaplan, 1989; Liprini, 2014). Studies conducted by Felsten (2009) and Kjellgren \& Burkhall (2010) measured the attention restoration of students exposed to green spaces. The researchers found that not only were green spaces conducive to restoring attention, but the students using them tended to be more relaxed and displayed increased levels of energy (Felsten, 2009; Kjellgren \& Burkhall, 2010). Other advantages of green spaces are that exposure to it lowers stress levels (Lewis, 1979; Speake et al., 2013); improves the ability to socialise (Speake et al., 2013); and enhances the personal quality of life (Maas et al., 2009). Although there was no significant relationship between the amount of time spent on campus and attention restoration, one can postulate that any amount of time spent in a green space will contribute to attention restoration and psychological well-being.

\section{Type of green space and attention restoration}

The results of the multiple regression analysis (table 7), revealed that all the green spaces included in the present study significantly contributed to the PRS scores. What is interesting, however, is that when the Beta-values of these spaces are studied, some spaces appear to have a greater influence on PRS scores than others. It is furthermore interesting to note that the spaces that contributed the most to the PRS scores are also the spaces that differed significantly from the 'other' category (table 6). As was previously mentioned, 'other' did not reflect real green spaces.

The greatest contributor to the PRS scores was Area E, the Manie van der Schijff botanical garden (beta $=0.247, p=0.000$ ). The large amount of plant variety, greenery, and tranquillity afforded by botanical gardens tend to make them more restorative than most other green and non-green areas (Ballantyne, Packer \& Hughes, 2008; Packer, 2010). Ward, Parker and Shackleton (2010), conducted research on botanical gardens in South Africa and discovered that 99\% of their participants indicated that exposure to botanical gardens is essential for their psychological well-being and personal quality of life. It is therefore not surprising that this area made the greatest contribution to the PRS scores. Area B made the second largest contribution (beta $=0.263, p=0.002$ ). This area incorporates a water feature. The highly restorative presence of a water feature serves as a possible explanation for why this area makes such a high contribution to PRS scores (White et al., 2010).

The area making the third greatest contribution was Area A (beta $=0.247, p$ $=0.003)$. This area contains a large lawn outside the Aula building, a type of auditorium. This area might be significant because not only is it near one of the campus's food courts, but it also allows students to sit on the lawn and socialise. As mentioned previously, green areas are important in facilitating socialisation (Speake et al., 2013). The fact that this area does not offer much shade or trees possibly explains why it did not contribute more to the PRS scores. Area C made the fourth largest contribution (beta $=0.236, p=0.004$ ). While this area outside the CSC is grassy and contains numerous trees, it is a very busy area. There are often campus events that take place in the food court right next to this green 
area. The noise and high traffic experienced as a result of this could explain why this green space was not rated as more restorative. The area making the smallest contribution was 'Area D' (beta $=0.164, p=0.029$ ). This area is intersected by a busy walkway and is opposite the local campus pub. It is possible that the lack of tranquillity one is afforded in this area contributes to the reason why this area makes the smallest contribution to perceived restorativeness.

Although the study highlighted the importance of green spaces of campuses, the results should be interpreted with caution since only one university's students participated in the study. It is hence important that future studies should incorporate more campuses. Another limitation of the study relates to the green spaces not receiving equal responses, which necessitated the grouping of green spaces together. Future studies should either increase their sample size or identify fewer green spaces to be incorporated into the study. As a result of these limitations, the results of the present study cannot be generalised to all campuses across South Africa.

\section{Conclusion}

The present study's findings indicate that students spending their free time on campus between lectures prefer to spend this time in green spaces. Green spaces do not only rejuvenate students suffering from mental fatigue, but also help to lower their stress levels and enhance their quality of life. The study further showed that spaces, such as botanical gardens that consist of a variety of trees, plants, and shrubbery, are deemed more restorative than spaces that facilitate socialisation.Although these findings cannot be generalised, supporting literature suggests that the experiences of green spaces on university campuses are similar globally. As a result of these findings, universities are implored to protect the green spaces on campus since it enhances students' well-being and assist with attention restoration. Students are therefore cognitively more rejuvenated when returning to lectures after spending time in green spaces. Although it is recognised that there is a growing need for hard spaces, they should not be developed at the expense of green spaces as they do not have the same restorative effects as green spaces and as such, would not contribute to students' overall well-being.

\section{References}

Abu-Ghazzeh, TM. (1999), 'Communicating behavioral research to campus design: Factors affecting the perception and use of outdoor spaces at the University of Jordan', Environment and Behavior, vol. 31, no. 6, pp. 764-804.

Ballantyne, R., Packer, J. and Hughes, K. (2008), 'Environmental awareness, interests and motives of botanic gardens visitors: Implications for interpretive practice', Tourism Management, vol. 29, no. 3, pp. 439-444.

Berman, M.G., Jonides, J. and Kaplan, S. (2008), 'The cognitive benefits of interacting with nature', Psychological Science, vol. 19, no. 12, pp.1207-12. 
Cohen, J.W. (1988), Statistical power analysis for the behavioural sciences, 2nd ed. New Jersey, Lawrence Erlbaum Associates.

Felsten, G. (2009), 'Where to take a study break on the college campus: an attention restoration theory perspective', Journal of Environmental Psychology, vol. 29, no. 1, pp.160-167.

Galindo, M.P. and Hidalgo, M.C. (2005), 'Aesthetic preferences and the attribution of meaning: Environmental categorization processes in the evaluation of urban scenes', International Journal of Psychology, vol. 40, no. 1, pp.19-27.

Herzog, T.R., Black, A.M., Fountaine, K.A. and Knotts, D.J. (1997), 'Reflection and attentional recovery as distinctive benefits of restorative environments', Journal of Environmental Psychology, vol. 17, pp. 165-170.

Kaplan, R. and Kaplan, S. (1989), The experience of nature: a psychological perspective, Cambridge, Cambridge University Press.

Kjellgren, A. and Buhrkall, H. (2010), 'A comparison of the restorative effect of a natural environment with that of a simulated natural environment', Journal of Environmental Psychology, vol. 30, no. 4, pp. 464-472.

Korpela, K.M. and Hartig, T. (1996), 'Restorative qualities of favorite places', Journal of Environmental Psychology, vol. 16, no. 3, pp. 221-233.

Korpela, K.M., Hartig, T., Kaiser, F.G. and Fuhrer, U. (2001), 'Restorative experience and self-regulation in favorite places', Environment and Behavior, vol. 33, no. 4, pp. 572-589.

Lewis, C.A. (1979), 'Healing in the urban environment: a person/plant viewpoint', Journal of the American Planning Association, vol. 45, no. 3, pp.330-338.

Liprini, RM 2014, 'Students' perceptions of green space on a university campus: An Attention Restoration Theory perspective' (unpublished master's dissertation), University of Pretoria, South Africa.

Maas, J., Verheij, R.A., Groenewegen, P.P., de Vries, S. and Spreeuwenberg, P. (2006), 'Green space, urbanity, and health: How strong is the relation?', Journal of Epidemiology and Community Health, vol. 60, no. 7, pp. 587-92.

Mcfarland, A.L., Waliczek, T. and Zajicek, J.M. (2008), 'The relationship between student use of campus green spaces and perceptions of quality of life', HorTechnology, vol. 18, no. 2, pp. $232-238$.

Merriam-Webster (2014), Green space, 15 November 2016, (https://goo.gl/e78fe8).

Purcell, T., Peron, E. \& Berto, R. (2001), 'Why do preferences differ between scene types?', Environment and Behavior, vol. 33, no. 1, pp.93-106.

Shah, M.G., Kale, C.M. and Patki, S.Y. (2002), Building drawing with an integrated approach to built environment, 4th ed. New Delhi, Tata McGraw-Hill Publishers.

Speake, J., Edmondson, S. and Nawaz, H. (2013), 'Everyday encounters with nature: Students' perceptions and use of university campus green spaces', Human Geographies - Journal of Studies and Research in Human Geography, vol. 7, no. 1, pp. 21-31.

Tenngart Ivarsson, C. \& Hagerhall, C.M. (2008), 'The perceived restorativeness of gardens - Assessing the restorativeness of a mixed built and natural scene type', Urban Forestry E' Urban Greening, vol. 7, no. 2, pp. 107-118.

Ward, C.D., Parker, C.M. \& Shackleton, C.M. (2010), 'The use and appreciation of botanical gardens as urban green spaces in South Africa', Urban Forestry $\mathcal{E}^{\circ}$ Urban Greening, vol. 9, no. 1, pp. 49-55. 